\title{
Self-Esteem and Academic Performance of freshmen at Karunya University
}

\author{
Jerylene Priyadharshini. J. ${ }^{1}$, Dr.Relton.A. ${ }^{2}$ \\ ${ }^{I}$ (Department of Social work, Research Scholar, Bishop Heber College (Autonomous), Bharathidasan \\ University, Trichirappalli, TamilNadu \\ ${ }_{2}^{2}$ (Department of Social work, Associate Professor\& Head, Bishop Heber College (Autonomous), \\ Bharathidasan University, Trichirappalli, TamilNadu)
}

\begin{abstract}
Self-esteem is an important academic construct in the process of education. It is how people feel about themselves and how much they like themselves, especially socially and academically when it comes to college students. Through the many pressures and daunting responsibilities of being a student, one learns and understands the importance of having a high self-esteem in college. Research has established that there is close relationship between self- esteem and academic achievements of freshmen students. A cross sectional/Descriptive study was carried out to examine the relationship between self-esteem and student's academic performance among the first year undergraduates in Karunya University, Coimbatore. The primary materials used were the Rosenberg self-esteem scale. Data were collected from 50 students of both boys and girls. The results demonstrated that students with positive self-esteem have high academic performance. Hence, it is inferred from the result of this study that there is a significantly high relationship between self-esteem and academic achievements of students.
\end{abstract}

Keywords: Self-esteem, Academic achievements of students.

\section{Introduction}

Self-esteem can be defined as one's overall sense of self-competence and self-worth. Self-competence, as defined by Romin W. Tafarodi and William B. Swann, is "a generalized sense of one's own efficacy or power". ${ }^{1}$ Simply put, self-competence is having self-confidence or the conviction that one is generally capable of producing desired results. Cognitively, self-competence is characterized by the presence of a generalized expectancy for success (Fibel and Hale, 1978). ${ }^{2}$

Self-worth or self-respect is essentially accepting oneself unconditionally and having the feeling that one is worthy of living and attaining happiness; you feel like you matter. As stated by Nathaniel Branden, if either selfcompetence or self-worth is absent, self-esteem is impaired. ${ }^{3}$

\section{Self-Esteem and Academic Achievement}

Numerous studies show a positive correlation between self-esteem and academic achievement (Barker, 1979; Brookover, Thomas and Patterson, 1964; Burns, 1979; Campbell, 1967; Caplin, 1966; Irwin, 1967; Lawrence, 1981; Mortimore, et al., 1988; Piers \& Harris, 1964; Purkey, 1970; Williams, 1973). ${ }^{4}$ However correlations does not imply causation. There is considerable disagreement among experts as to which come first - high self-esteem or academic achievement. It does appear that the relationship between self-esteem and academic performance is bidirectional i. e. self-esteem and academic achievement influence each other.

Several studies show that self-esteem influences academic performance (Haarer, 1964; Jones and Grieneekz, 1970; Lamy, 1965; Morse, 1963; Smith, 1969; Wattenberg and Clifford, 1964). Research has shown that self-esteem is a better predictor of academic success than measured intelligence (Morse, 1963; Smith, 1969; Wattenberg and Clifford, 1964). ${ }^{5}$ Research aside; common sense dictates that our thoughts influence our feelings and behaviour. Our behaviour, consequently, influences our performance. Life is essentially a selffulfilling prophecy. Common sense also dictates that a student who has self-doubt and lacks self-acceptance is unlikely to attain academic excellence. How can a student establish challenging goals if he or she lacks a sense of self-competence or self-efficacy? How can a student concentrate fully on studies if he or she lacks selfapproval? Indeed, research does show that underachievers are generally less confident and less ambitious, (Goldberg, 1960), less self-accepting (Shaw and Alves, 1963), and lack a sense of personal worth (Durr and Schmatz, 1964). ${ }^{6}$ Research also shows that feeling worthless can be depressing (Battle, 1990; Bhatti, 1992; Hokanson, Rubert, Welker, Hollander, \& Hedeen, 1989) and depression generally inhibits performance. ${ }^{7}$ As stated by Mark R. Leary and Deborah L. Downs, "People who feel worthy, able, and competent are more likely to achieve their goals than those who feel worthless, impotent, and incompetent." ${ }^{8}$ 
Research shows that academic achievement influences the level of self-esteem. Successful academic performance enhances self-esteem (Bills, 1959; Carlton and Moore, 1966; Diller, 1954; Robinson, Kehle, \& Jenson, 1986). ${ }^{9}$ similarly; poor academic performance tends to erode students' level of self-esteem (Centi, 1965; Gibby \& Gibby, 1967). ${ }^{10}$

\section{Empowering Cycle of High Self-Esteem}

The reciprocal relationship between self-esteem and academic achievement is best exemplified in the Empowering Cycle of High Self-Esteem and the Vicious Cycle of Low Self-Esteem which I have recently developed based on literature research. As shown in Figure 1, high self-esteem fosters high expectations. Research shows that individuals with high self-esteem are more confident than those with low self-esteem that their efforts will lead to success (Baumgardner, 1990; McFarlin \& Blascovich, 1981). ${ }^{11}$ Research also generally shows that feelings of self-competence are conducive to higher levels of intrinsic motivation (Bandura \& Cervone, 1983; Deci \& Ryan, 1985; Harackiewicz \& Larson, 1986; Harter \& Jackson, 1992; Vallerand, 1983). ${ }^{12}$ In short, students with high self-esteem tend to be more ambitious than those with low self-esteem.

High expectations facilitate the establishment of challenging goals. Individuals with high self-esteem generally undertake more challenging goals than do individuals with low self-esteem (Bandura, 1989; Waschull \& Kernis, 1996). ${ }^{13}$

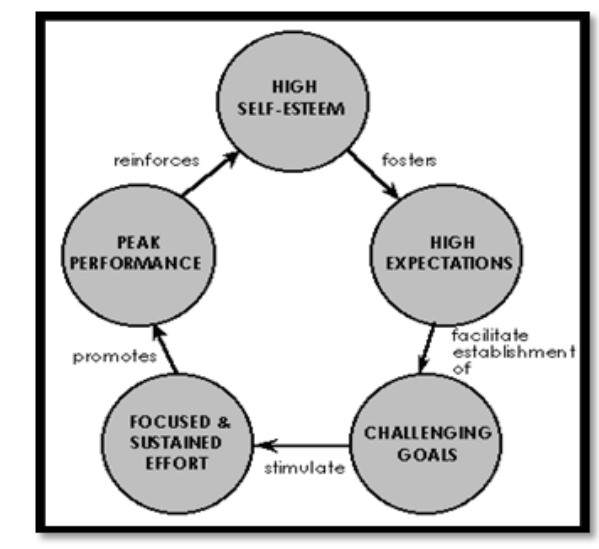

FIGURE 1: Empowering Cycle of High Self-Esteem

Challenging goals help to stimulate focused and sustained effort. Students who have a strong sense of efficacy or self-competence tend to focus their attention and effort on the demands of tasks and to minimize potential difficulties (Bandura, 1986; Cauley, Linder and McMillan, 1989). Persons with high self-esteem perform better after an initial failure than persons with low self-esteem and are more likely to persevere in the face of obstacles (Brockner, 1979; Perez, 1973; Schalon, 1968; Shrauger \& Sorman, 1977). ${ }^{14}$ Indeed, selfesteem is a key variable in determining resilience (Rutter, 1985; Werner, 1993). ${ }^{15}$

Focused and sustained effort promotes attainment of peak performance (consistent and outstanding scholastic performance) which consequently reinforces feelings of high self-esteem. As stated by Nathaniel Branden, reaching demanding and worthwhile goals nurtures good self-esteem. ${ }^{16}$

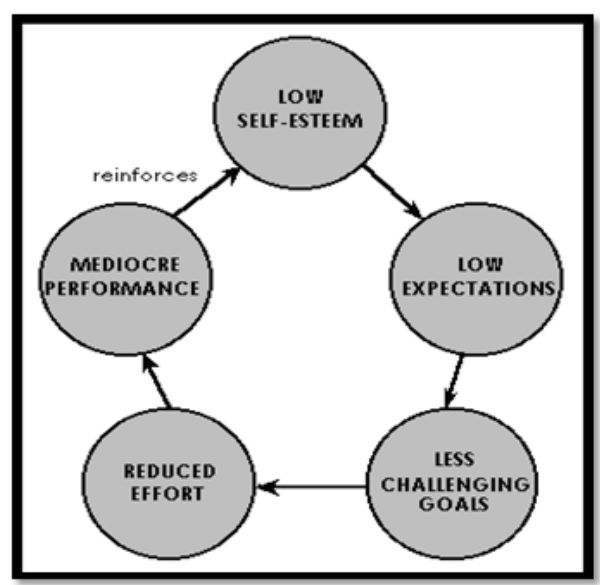

FIGURE 2: Empowering Cycle of Low Self-Esteem 


\section{Vicious Cycle of Low Self-Esteem}

As shown in Figure 2, low self-esteem generally results in low expectations. Research shows that, relative to high self-esteem people, low self-esteem people set lower expectations for their performance in a variety of situations (Coopersmith, 1967; Kiesler \& Baral, 1970). ${ }^{17}$

People with low self-esteem generally underestimate their capabilities primarily because they lack a realistic knowledge of their own abilities, they lack self-confidence or because they are threatened by failure. ${ }^{18}$ Low expectations naturally result in the establishment of less challenging or mediocre goals. Research shows that the lower the children's self-esteem, the lower their preference for challenge. ${ }^{19}$ Less challenging goals consequently lead to reduced effort and mediocre performance (Campbell \& Fairey, 1985; Diggory, Klein, \& Cohen, 1964; Wattenberg and Clifford, 1964) ${ }^{20}$ Mediocre performance ultimately reinforces one's feeling of low self-esteem. Research shows that students who underachieve academically or who fail to live up to their own academic expectations, suffer significant losses in self-esteem (Centi, 1965; Gibby and Gibby, 1967). ${ }^{21}$

\section{Statement of the problem}

Self-esteem positively co-relates with increased academic performance of students. Research studies show a highly close relationship between academic achievements of students and their self-esteem. Most studies have concluded that students with high level of self-esteem have high level of academic achievements (Owen, 1992). The study specifically investigates teachers' perception of relationship between self-esteem and academic achievements of government secondary school students.

\section{Research Objectives}

1. Explore the perceptions of teachers regarding the relationship between self-esteem and

2. Students' academic achievements.

3. Discover the impact of self-esteem upon the academic achievements of students

4. Find out the benefits of self-esteem for students in the process of education.

\section{Research questions}

This research study attempts to answer the following questions;

1. What are the perceptions of teachers regarding the relationship of self-esteem with academic achievements of students?

2. How self-esteem impacts academic achievements of students?

3. What are the previous studies about the relationship of self-esteem and students' academic achievements?

4. What are the benefits of high self-esteem for students?

5. How self-esteem of students could be improved?

\section{Literature Review}

Self-esteem and academic achievement have close relationship and have a lasting impact each other. High self-esteem plays a highly important role not only in academic achievements of students but also in social and personal development as well (Pullmann and Allik, 2008). According to Galbraith et al. (2011) self- esteem is a feeling that guides individuals' behaviour. It is a driving force behind motivation. In the words of Wiggins (1987) self-esteem is the ability of an individual to deal with different challenges of life. It is the feeling of being worthy to do something extra ordinary, to enjoy the right and the ability to do hard work. Amini (2004) explains that self-esteem is the overall self-evaluation in a positive way. It is the belief that one has to be competent and worthy enough to achieve something in life. Simply speaking, it is a feeling of self-competence and self-worth. According to Woolfolk (2005) self-esteem is the worth or value that individuals attach to their self-assessments.

Anthony et al. (2007) argue that students with high self-esteem have comparatively high academic achievements than students with low self-esteem. Self-esteem affects all aspects of the life of an individual, such as, job success, school achievement, social development and professional development. However, there is a close relationship between self-esteem and level of educational attainment of learners (Wiggin et al 1994). For .example, in one their studies Maruyama et al (2008) have found that students who generally feel confident show better performance.

The degree of relationship of the students is conditioned by the level of self-esteem either positively or negatively. Positive high self-esteem enables students to develop positive relationship with peers, teachers and even with a common man. Low self-self-esteem breeds in students feelings of deficiency and inability. Such students feel rejected which dangerously affects the performance of the students in the process of education (Supple, 2000). High level of self-esteem facilitates the students to achieve the goals of life whatever, because it develops in an individual coping skills, confident and feelings of worthiness. Similarly, Grantham and Ford (2003) elaborate that students with high self-esteem set higher goals in life and strive to achieve them with 
determination, commitment and steadfastness. Such students do not lose hope even in the face of failures. Because, such students have never ceasing belief and the will to attain the goal and they achieve it ultimately.

However, it has been discovered by Chiu (1990) that students with low self-esteem usually lose hope and confidence in the face of failures, criticism and rejection. Such students suffer from anxiety or depression which finally results in the withdrawal from the attempt or efforts to achieve the goal. Dawes (1998) elaborates students with low self-esteem do not always seem active or diligent enough to use variety of strategies or solutions when it comes to challenging tasks. Therefore, Delacourt (1997) argues that self- esteem is one of the essential catalysts of education to enable learners to reach the highest potential of development in all spheres of life, be it social, intellectual, moral and physical. Hence, self-esteem is positively correlated with academic outcomes.

\section{Population and Sampling:}

\section{Research Methodology}

This is a descriptive research design .To comply with the objectives of this study, 50 freshmen students were selected. The mean age of the students was 19. According to Oyinloye (2010) descriptive method helps researchers to identify what is happening in order to predict the future. Students were stratified based on gender such that equal number of participants represented each of the two genders ( 25 male and 25 female).

\section{Research Tools /Instruments:}

The researcher designed and administered a questionnaire which contained 20 items based on Five Point Likert Scale to rate the level of self-esteem and its effects on academic achievements of students. The study investigated the perceptions of teachers about relationship between self- esteem and academic achievements of students in the following areas.

1. $1^{\text {st }}$ Semester Examination marks

2. Classroom participation

3. Students learning

\section{Results and findings}

\section{Analysis Of The Data}

The scores from the questionnaires were collected, organized, collated and presented in percentage statistics. The analysis of the data is given in the below tables.

\section{Respondents' views on the relationship between self-esteem and $1^{\text {st }}$ Sem -examination results}

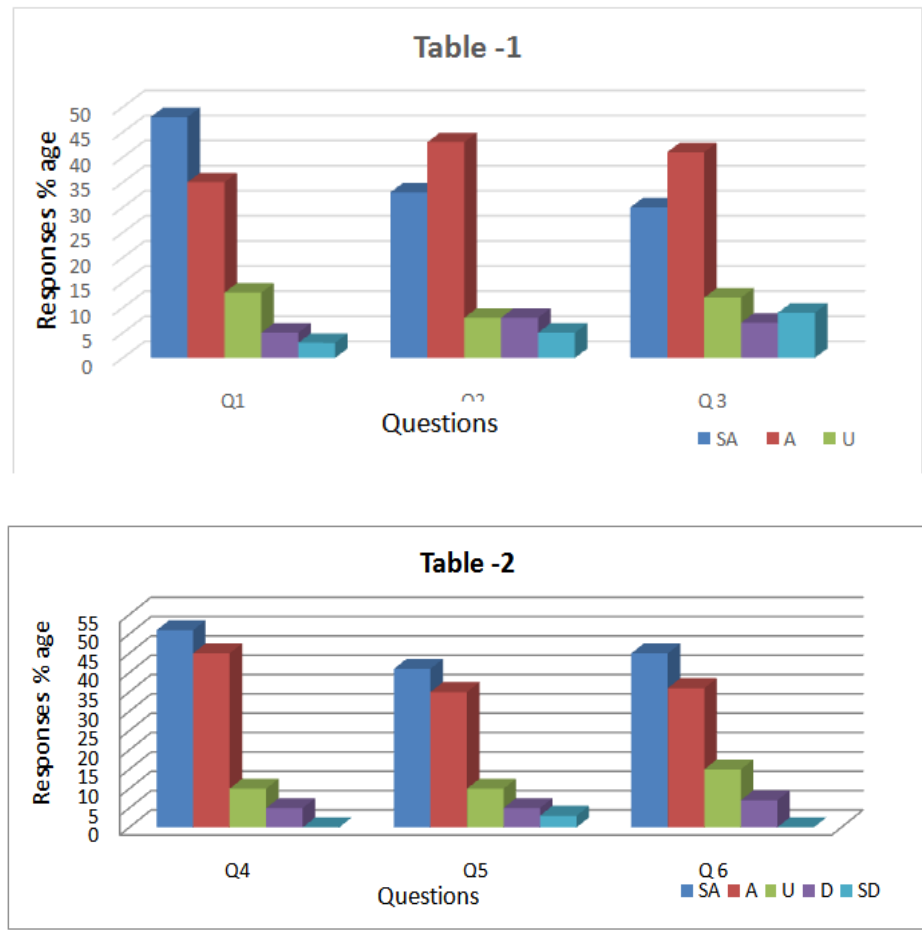


The results presented in table 1 and 2 shows that majority of the teachers (45\%) strongly agree that student with high self-esteem manage their examination time more effectively. Similarly, $42 \%$ were of the opinion that students who have high self-esteem can ask for clarifications for teachers with confident. Coincidently, $41 \%$ of the teachers also believe that students with high self-esteem make preparations for their examination well in time. At the same time, $44 \%$ teachers strongly disagreed to the statement that those students who have high self-esteem feel shy to ask questions from their teachers in classroom. Majority of the teachers, $51 \%$ strongly agreed to the statement that students with high self-esteem have the ability to express their ideas clearly on the examination answer sheets. Similarly, $41 \%$ agreed that students with high self-esteem have clear and legible writing which others can understand easily. $44 \%$ of the teachers strongly agreed to the statement that students with high self-esteem are able to understand questions asked in the examination without any difficulty.

\section{Respondents' views on the relationship between high self-esteem and classroom participation of students}


Results presented in Table 3 and 4 show that $44 \%$ of the teachers strongly agree that students with high self-esteem have positive attitude towards their class mates. More than $45 \%$ strongly disagree that students with high self-esteem share views in the classroom without any confident. $40 \%$ of the teachers strongly agree that students with high self-esteem take part in classroom activities without any hesitation. Similarly, $44 \%$ were strongly of the view that students with high self-esteem feel shy to ask questions from teachers in the classroom. More than $43 \%$ teachers also strongly agreed that students with high self- esteem show leadership in classroom activities during teaching and learning. Similarly, $43 \%$ were of the view that students with high self-esteem show high interest in classroom activities.

Moreover, more than $40 \%$ were strongly of the view that students with high self-esteem cooperate and collaborate with their classmates during the teaching and learning process. 


\section{Respondents' views on the relationship between students' learning and self-esteem}
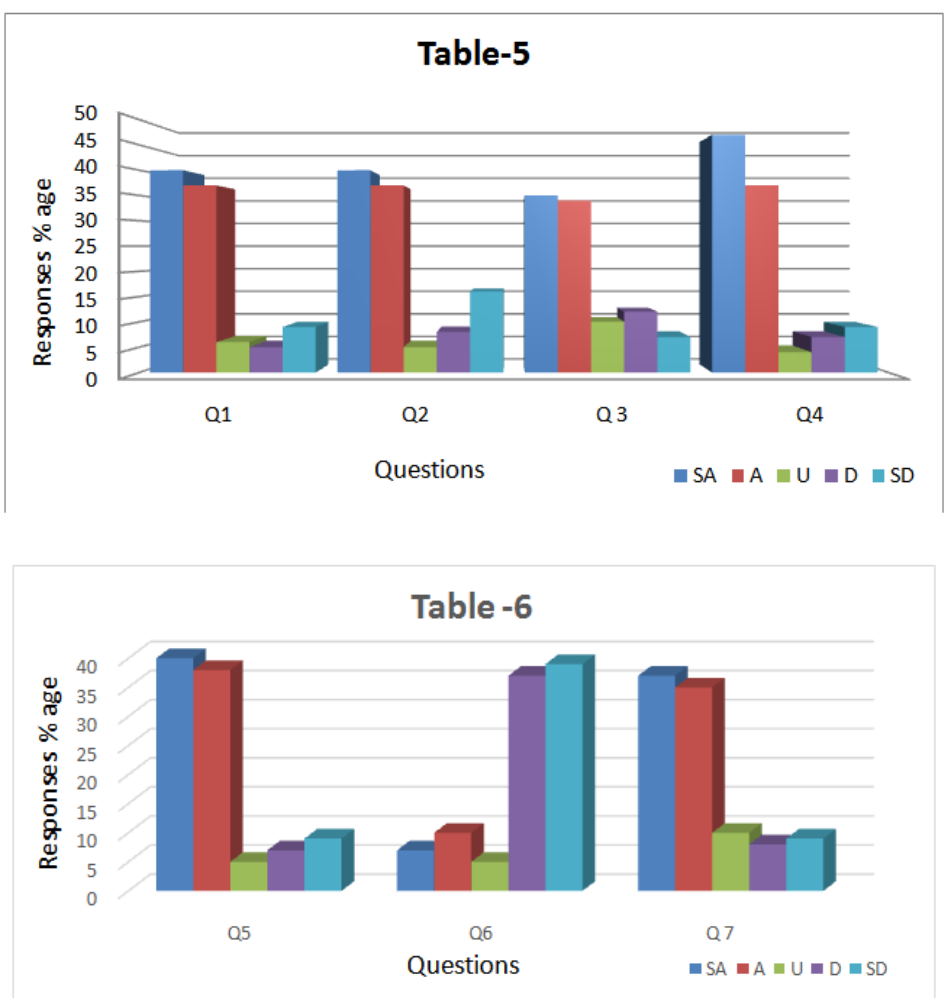

Results presented in table 5 and 6 shows that majority $40 \%$ of the teachers strongly agree students with high self-esteem have motivation for learning. Similarly, $40 \%$ strongly agree that such students show creativity in educational performance. A large majority $42 \%$ also strongly agree that students with high self-esteem observe social skills in the classroom during teaching and learning process. $42 \%$ of the teachers further strongly agree that such students enthusiastically participate in the classroom activities. In the same way, $40 \%$ also strongly agree that students with high self-esteem do their class assignments well in time.

More than 39\% strongly disagree that student with high self-esteem remain passive most of the time during teaching and learning process. More than $37 \%$ of the teachers strongly agree that students with high self-esteem cooperate with their teachers in the process of teaching and learning by performing the assigned duties effectively and efficiently.

\section{Conclusion}

The above analysis shows that majority of the teachers have strongly agreed to the statements which favour the effects of high self-esteem on student's higher rate of interests in classroom activities, confident, positive attitudes towards classmates, sense of collaboration, motivation for learning and sharing of views in classroom discussions. Thus it is interesting to find out on the basis of this study that there is a very highly significant corelation between self-esteem and degree of academic achievements of students. Finally, on the basis of this study it may be concluded that self-esteem has deeper positive effects upon academic achievements of students as freshmen.

\section{References}

[1]. Beane, J.A., \& Lipka, R.P. (1986). Self-Concept, Self-Esteem, and the Curriculum. New York: Teachers College

[2]. Colardarci, T., McCaul, E.J., Donaldson, G.A., \& Davis, W.E. (1992). Consequences of dropping out of high school: Findings from high school and beyond. Journal of educational research, 85, 198-207

[3]. Chiu, L. H. (1990). The relationship of career goal and self8 esteem among adolescents. Adolescence, 25, 433-451

[4]. Dawes, R. M. (1998). The social usefulness of self-esteem: A skeptical review. The Harvard Mental Health Letter, 15 (4), 4-5.

[5]. Jordon, L.K., \& Kelly, K.R. (1990). Effects of academic achievements and gender on academic and social self-concept: A replication study. Journal of counseling and development, 69,173-177 Kingsbury,

[6]. G.G., Maruyama, G., \& Rubin, R.A. (1981). Self-esteem and educational achievements: independent constructs with a common cause. Journal of personality and social psychology, 40, 962-975

[7]. Marsh, H. W., \& O’Mara, A. (2008). Reciprocal effects between academic self-concept, selfesteem, achievement, and attainment over seven adolescent years: Unidimensional and multidimensional perspectives of self-concept. Personality and Social Psychology Bulletin 5 (34) pp.32-45 Maruyama, G. M., Rubin, R. A., \& Kingsbury, G. G. (1981). Self-esteem and educational achievement: Independent constructs with a common cause? Journal of Personality and Social Psychology, 40(5), pp. 623-655. 